\title{
Bloqueo de la fascia clavipectoral guiado por ultrasonido
}

\author{
Labandeyra H. ${ }^{1}$, Roqués Escolar V. ${ }^{2}$, Valdés Vilches LF. ${ }^{3}$ \\ 1 Hospital Abraham Piñeyro, Junín, Argentina. \\ 2 Hospital Virgen de Arrixaca, Murcia, España. \\ 3 Hospital Costa del Sol, Marbella, Argentina.
}

Introducción: El bloqueo de la fascia clavipectoral (CBP) es un bloqueo que proporciona anestesia/analgesia exclusiva sobre la clavícula en fracturas de tercio medio, sin producir bloqueo motor de miembro superior ni parálisis diafragmática.

Presentamos un caso de CBP guiado por ultrasonido para control del dolor perioperatorio en osteosíntesis clavicular tras fractura de tercio medio.

Métodos: Mujer de 18 años de $60 \mathrm{~kg}$ con fractura de tercio medio clavicular derecho. Antecedentes de alergias a antiinflamatorios no esteroides y contraste iodado. Se programa para osteosíntesis de clavícula. Se decide realizar anestesia regional con CPB asociada a sedación superficial.

Antes de la realización del procedimiento se evaluó el dolor del paciente mediante escala visual numérica (EVN), siendo esta de $7 / 10$.

Previamente a la realización de la técnica descripta, se realizó infiltración de la rama supraclavicular del plexo cervical superficial con $5 \mathrm{ml}$ de ropivacaína $0,5 \%$ para obtener anestesia de la zona cutánea correspondiente. Posteriormente y realizando cortes sagitales sobre la clavícula con transductor lineal de 6-13 mhz se identificó el extremo distal y proximal de la fractura. Tras clara identificación de periostio clavicular intacto a ambos lados de la fractura, fascia clavipectoral, musculo pectoral mayor y subclavio. Se realizó infiltración en plano, de caudal a cefálico, mediante aguja de $50 \mathrm{~mm}$ entre el periostio y fascia clavipectoral. El volumen total empleado fue de $15 \mathrm{ml}$ de ropivacaína $0,5 \%$ a cada lado de la fractura y sobre el borde superior de la clavícula, observando clara elevación fascial.

La cirugía se llevó a cabo sin complicaciones ni dolor.

Resultados: Una vez realizada la conducta quirúrgica se evaluó el dolor del paciente con EVN, siendo esta 1/10 hasta 36 horas postoperatorio. No fue necesario rescate analgésico durante su estancia hospitalaria. No se observó posible bloqueo motor de miembro superior o diafragmático.

Conclusiones: El bloqueo CPB permite una anestesia/analgesia de gran calidad en cirugía de tercio medio clavicular. Aunque sus indicaciones son limitadas, presenta grandes ventajas respecto a los bloqueos tradicionales del plexo braquial empleados para la misma patología como ser de muy fácil ejecución, sin bloqueo motor acompañante, ni parálisis diafragmática. Todo ello lo hace una opción muy recomendable en este tipo de patología, en la que resulta de gran interés el alta precoz, sin dolor, y evitando posibles efectos secundarios.

Aunque aún no existen estudios que la validen, se presenta como una técnica prometedora para la cirugía realizada sobre la clavícula.

https://doi.org/10.25237/congresoclasa2019.28 